\title{
The Exploration of Mechanism and Path of the Integrated Development of Cultural Industry and Tourism Industry
}

\author{
Xue Jia \\ Chengdu Polytechnic. Sichuan, Chengdu, China
}

Keywords: cultural industry; tourism industry; integrated development; mechanism; path

\begin{abstract}
Culture is the crystallization and wisdom of human development experience, and plays an important role in enriching people's spiritual life. With the development of modern social economy, people's living standards have been continuously improved, and the consumption and enjoyment of spiritual culture has been increasing, and cultural tourism has developed rapidly. This paper mainly discusses the mechanism and path of the integrated development of cultural industry and tourism industry in the context of information age.
\end{abstract}

\section{Introduction}

In recent years, with the improvement of the living standards of the residents and the adjustment of the national industrial structure, the development of the cultural industry and the tourism industry has made great progress. The combination of the two - the development of cultural tourism is more rapidly. The integration of cultural industry and tourism industry not only conforms to the overall requirements of the national development strategy, but also brings people the enjoyment of culture and beauty while promoting the cultural industry and the tourism industry, and it is of great significance to the improvement of people's cultural literacy and the development of the national economy.

\section{A Brief Introduction to Cultural Industry and Tourism Industry}

\subsection{The meaning of cultural industry and tourism industry}

As a professional term, the cultural industry originated in the early 20th century and refers to the influence of culture as a special economic form on the development of the national economy. The UNESCO's definition of the cultural industry is "a series of activities that produce, reproduce, store and distribute cultural goods and services in accordance with industry standards”[1]. Compared with developed cultural industries countries such as Europe and the United States, China's current cultural industry is still in the early stages of development. However, with the adjustment of national development policies and guidelines, in recent years, China's cultural industry has made great achievements.

The tourism industry is the link between tourism consumers and tourism resources. It takes tourists as the objective of development and service. It is a comprehensive industry that provides services and convenience for tourists' tourism process. It is characterized by comprehensive, professional, centralized, monopolistic and competitive coexistence. It consists of three major elements: tourism resources, tourism facilities and tourism services ${ }^{[2]}$. With the change of people's consumption concept, more and more people are engaged in tourism industry or participate in tourism consumption. The tourism industry has developed rapidly and has become a new pillar industry for national economic development.

\subsection{The relationship between cultural industry and tourism industry}

The relationship between the cultural industry and the tourism industry is very close.

First, the cultural industry and the tourism industry contain overlapping parts. For example, cultural and recreational services include tourism and cultural services (scenery management, park 
management, wildlife protection, animal and plant viewing, etc.). These are the overlapping parts of the cultural industry and the tourism industry. They have both the characteristics of a cultural industry and the characteristics of a tourism industry.

Second, the cultural industry and the tourism industry promote each other. Generally, tourism resources and tourism behaviors are more or less the shadow of culture. Many scenic tourist attractions have local characteristics and cultural flair. People can feel it while enjoying the scenery. For culturally knowledgeable tourists with clear objectives, their tourism purposes are more obvious. Their behavioral process has both tourism and cultural factors, which contribute to the common development of the cultural industry and the tourism industry.

Finally, the integration of the cultural industry and the tourism industry is deepening. In recent years, the cultural industry factors contained in the tourism industry have become increasingly more. The development strategy of national cultural rejuvenation and the present development status that people's demand for a better life is increasing require to vigorously develop the cultural industry, readjust the industrial structure, enhance the scientificity and rationality of the development of industrial structure, and speed up industrial convergence. Therefore, in order to achieve rapid and healthy development of the industry, the integration of cultural industries and tourism industry is becoming more and more advanced.

\section{The Necessity and Significance of the Integrated Development of Cultural Industry and Tourism Industry}

First, the needs of national development strategies.

Although China's economic strength and overall national strength are rising, the development speed of the cultural industry is relatively backward, becoming a defective industry for the development of the national economy. In this regard, in order to achieve the overall development of the national economy and the revival and prosperity of Chinese culture, The Sixth Plenary Session of its Seventeenth Central Committee of Chinese put forward the strategic goal of "building a strong socialist culture". In order to achieve the strategic goal of "culturally strong country", we must accelerate the development of cultural industries and enhance the soft power of national culture. Therefore, the tourism industry, which is closely related to the cultural industry, must also be made adjustments at the same time. It should be developed rapidly to realize the deep integrated development of cultural and tourism industries.

Second, the need for economic restructuring. China has been a big agricultural country since ancient times $^{[3]}$. Since modern times, especially after the founding of the People's Republic of China, the state has vigorously developed the industrial industry. Up to now, China's agriculture (primary industry) and industry (second industry) have achieved fruitful results. But at the same time, China's economic development has also had some problems: First of all, the proportion of industrial structure is seriously out of balance. The development of the tertiary industry is relatively backward and cannot meet the growing needs of the people for a better life; Second, the speed of cultural development is relatively slow. Many excellent traditional cultures have been lost, and the impact of foreign cultural concepts has become more and more important; Finally, the degree of integration and coordination between industries is low. Generally speaking, the integrated development of the cultural industry and the tourism industry is the need to adjust China's economic structure and promote the coordinated development of various industries.

Third, the integrated development of cultural industry and tourism industry can play a powerful role and significance. First of all, from the perspective of the development of its own industry, the development of traditional cultural industries and tourism industries are all "independent", with little attention to the relationship between the two and other related industries. The integrated development of the cultural industry and the tourism industry will help the two to quickly recognize the shortcomings of their own industry development, absorb and learn experience and advanced models of the development in other industries, improve the industrial development and innovation capabilities and create vitality, and realize the scientific and diversification of the industry development; Secondly, from the perspective of national economic development, cultural industries 
and tourism industries belong to the tertiary industry of national economic development. The integrated development of the two is conducive to providing examples and methodological guidance for other industries in the tertiary industry, thereby promoting the development and growth of China's tertiary industry and enhancing the country's cultural strength; Finally, judging from the trend of international development, China is in the midst of a new round of historical development in the world. The exchanges between countries and ethnic groups are deepening, and the collision between culture and economy is increasing. The integrated development of cultural industry and tourism industry can enhance the ability to resist external unhealthy ideological culture and malicious economic competition and enhance the competitiveness of Chinese culture and economy.

\section{The Mechanism and Path of the Integrated Development of Cultural Industry and Tourism Industry}

\subsection{The problems of cultural industry and tourism industry in the integrated development}

First, it is necessary to deeply understand the relationship between the cultural industry and the tourism industry and the significance of the integrated development of the two. Many leaders do not have a deep understanding of the close relationship between the cultural industry and the tourism industry, or the understanding of the relationship between the two is only on the surface of the cross-cutting business, lacking a deep recognition of the commercial value that can be produced by the connection between the two. The problem that they are not able to deeply understand the connection between the two and the huge economic benefits and deep value that these linkages may generate is the first major obstacle affecting the integrated development of the cultural industry and the tourism industry that .

Second, grasp the degree of integrated development, and improve the problems existing in the construction of various mechanisms. The integration and development of cultural industry and tourism industry should pay attention to avoiding the loss of "excessive" dependence on the independence of industrial development, and also avoid the lack of diversity caused by the excessive "independence" of industrial development ${ }^{[4]}$. On the other hand, the development of China's modern cultural industry started late, and the degree of development is still at an early stage. There is still a lot of room for improvement and. For the integrated development of tourism industry, there are still many areas for improvement in mechanism construction. For example, in terms of personnel management and assessment mechanism, it is necessary to strengthen and improve the assessment standards of relevant practitioners and improve their professional service level. Many tourist resort staff, such as tour guides, etc., have different quality of work, or have little knowledge of local customs and culture, or low professionalism, bad attitudes towards tourists and local residents, etc. These need to be improved in the management system. .

Third, combined with the development of the local practice.The integration of different industries needs to take into account the actual situation of industrial development, especially for the integrated development of cultural industries and tourism industries. Every region and even villages will form a culture with their own characteristics. The tourism resources of each region vary greatly depending on cultural customs and so on. However, many cultural enterprises and tourism companies have not developed their development strategies and plans according to the actual situation of the localities. The development targets formulated have shown obvious characteristics of "false, large and empty", resulting in the local tourism culture being developed ineffectively. The promotion of tourism companies and cultural companies does not match the actual situation, which seriously affects the development of corporate reputation and local tourism culture.

\subsection{The mechanism and path of the integrated development of cultural industry and tourism industry}

First, strengthen the understanding of the leaders of relevant enterprises on the significance of the integration of cultural industries and tourism industry. From the perspective of government 
departments, relevant government departments should not only formulate reasonable market development guidance plans, but also strengthen cooperation on industrial integrated development cooperation, and provide more convenient conditions and preferential policies for industrial cooperation; From the perspective of industrial development, the leaders of the cultural industry and the tourism industry should strengthen their understanding and reflection on the development of their own industries, deepen their understanding of related industries, and create more possibilities for industrial cooperation.

Second, improve the construction of cooperative development mechanisms. The current mechanism for the integration of cultural industries and tourism industry is still not perfect. In this regard, the government departments should strengthen the improvement of relevant laws and regulations, and provide corresponding legal and policy guidance and assistance; Enterprises should strengthen the management mechanism, assessment and evaluation mechanism (such as strengthening the staff's level supervision and cross-level supervision mechanism, gradually expanding the scope of assessment, etc.), as well as service mechanism, etc., so as to provide institutional guarantee for the smooth progress of the integration and development between the cultural industry and the tourism industry.

Third, formulate scientific and rational development strategies and plans. Every enterprise development has its own goals, which are based on their own development plans. The integrated development of the cultural industry and the tourism industry must also formulate a strategic plan that is in line with local cultural characteristics and suitable for the development direction of the cultural industry and the tourism industry. For example, Jingdezhen City in Jiangxi Province should focus on porcelain culture as the main propaganda focus, and build the capital of Chinese porcelain culture. Luoyang takes peony as the focus of cultural tourism promotion and development, and builds an internationally renowned Peony Culture City. Formulating development plans based on their actual characteristics is a necessary condition for the successful development of cultural industry and tourism industry.

Fourth, strengthen the cultivation of compound talents. The integration of cultural industry and tourism industry must have sufficient professional talent team support. Moreover, this talent team must not only have a deep cultural knowledge and professional level of cultural industry development, but also possess high-level tourism expertise and skills to meet the strategic development needs of both the cultural industry and the tourism industry. In this regard, enterprises and related training institutions and the government must provide more and more comprehensive training content and practical training opportunities for relevant talents, strengthen the assessment of employees, and promote continuous improvement of employees and improve their professional level.

\section{Conclusion}

The cultural industry and the tourism industry are two closely related industrial projects, and they belong to the tertiary industry. In the context of the adjustment of the industrial structure, the national implementation of the strategy of "cultural power strategy" and the accelerated promotion of the Chinese cultural revival, when strengthening the integrated development of cultural industry and tourism industry, many problems should be paid attention to. We should not only see problems encountered in development, but also have the determination and confidence to overcome difficulties. Finding countermeasures from the problems, prescribing the right medicine, accelerating the integrated development of the cultural industry and the tourism industry and the adjustment of the industrial development structure to promote the sustainable and healthy development of the two.

\section{References}

[1] Dailin Pan. Research on the path of integration and development of cultural industry and tourism industry from the perspective of cultural consumption -- Taking Xianju County of Zhejiang 
Province as an example[J]. National Geographic, 2016(2).

[2] Yun Zou. Research on the integratED development mechanism of tourism industry and cultural creative industry -- Taking Chengdu city of Sichuan Province as an example[J]. Reformation \& Strategy, 2017(7):126-128.

[3] Li Tang, Huiling Kang. Research on the integrated development of cultural industry and tourism industry in Southern Fujian -- Taking Dongshan Guandi cultural tourism festival as an example[J]. Journal of Guangxi Teachers Education University, 2016, 37(6):92-96.

[4] Liyun Wu. Research on the integrated development mode of cultural and tourism industry from the perspective of industrial chain[J]. Journal of Taishan University, 2016, 38(6):12-16. 